\title{
Investigation, assessment and remediation of levee transitions
}

\author{
Jonathan Simm¹,a, Bridget Woods Ballard ${ }^{1}$, Jaap-Jeroen Flikweert², Eva van Maren², Aggelos Dimakapoulos ${ }^{1}$, Mohamed \\ Hassan $^{1}$, Robert Kinnear ${ }^{3}$, Matt Arthur ${ }^{3}$. Rémy Tourment ${ }^{4}$, Christina Neutz $^{5}$ and Paul van Steeg ${ }^{6}$ \\ ${ }^{1}$ HRWallingford, Howbery Park, Wallingford, Oxfordshire OX10 8BA, United Kingdom \\ ${ }^{2}$ RoyalHaskoning DHV, Rightwell House, Bretton, Peterborough PE3 8DW, United Kingdom \\ ${ }^{3}$ Environment Agency, Horizon House, Deanery Rd, Bristol BS1 5AH \\ ${ }^{4}$ INRAE, Route Cézanne 3275, 13100 Aix-en-Provence, France \\ ${ }^{5}$ US Army Corps of Engineers, Louisville District, 600 Dr Martin Luther King Jr PI, Louisville, KY 40202, USA \\ ${ }^{6}$ Deltares, PO Box 177, NL2600MH Delft, the Netherlands
}

\begin{abstract}
Transitions between levees (earthen flood embankments) and other hard structures are areas of weakness within an overall system of flood defences and can be found at any location, on or within a flood defence where there is a change in flood defence structure or of protection revetment (slope or crest, road, etc.), in an internal cross section and in the construction or foundation materials. The transition typically promotes the processes of internal and external erosion. If these processes are undetected, or left unchecked, they can ultimately lead to flood defence failure and breach. Historical floods indicate that most levee failures occur around transitions as illustrated by well-known cases such as the levee failures in New Orleans during hurricane Katrina, and by the findings from reviews of levee performance during UK flood events since 2007. That transitions often form weak points within a defence system is recognised internationally, and agencies and organisations - particularly within the Netherlands, France and USA have directed effort to understand how transitions affect overall defence performance and how these impacts should be addressed within an overall risk based approach to their management. Some of this work is reflected in the International Levee Handbook. However, current guidance in England and Wales on the visual inspection of flood defence asset does not explicitly account for the potential effects of transitions on defence performance. Likewise, current methods of assessing defence performance also fail to directly account for the increases in loading and reductions in strength arising at interfaces. Guidance on the design detail of transition zones is also limited to that for new defences provided by the International Levee Handbook. The Environment Agency in the UK therefore teamed up with a group of international experts to conduct research to consider the presence of interfaces during flood defence condition assessment, quantify the effects of interfaces on flood defence performance (as expressed by fragility curves), and produce design guidance for retrofitting existing interfaces. This paper describes the outcomes of the research.
\end{abstract}

\section{Introduction}

A transition (see e.g. Figure 1) is a single point or a zone in a flood defence structure where features such as structure type, material, geometry, subsoil or orientation change in a way that can materially affect the performance or integrity of the structure during a flood. Transitions of concern almost always involve a link to a levee (earthen embankment). Connections between structural flood walls and levees and crossings of utility infrastructure such as culverts or pipes through or over a levee are examples of transitions.

The physical processes that occur at transitions, if undetected or left unchecked may impact the deterioration process of their condition and can ultimately lead to flood defence failure and breach. Transitions may result in

- increases in loadings on specific areas of the transition (resulting from the interaction of transition features with local flowpaths)

- reductions in the resistance of the defence to loadings;

Impacts of transitions (see Figure 2) may relate to

1. Geometry (shorter seepage paths; steeper slopes; or irregular geometry causing turbulence).

2. Differences in behaviour of materials (hydraulic separation and strain incompatibility; impeded grass root formation and shading; or gaps in filter structures). 
3. Impediments to construction and maintenance (poor compaction around transition elements; or impeded maintenance due to poor access and visibility).

4. Preferred paths for humans or animals causing deterioration (rutting and furrowing; animal burrows).

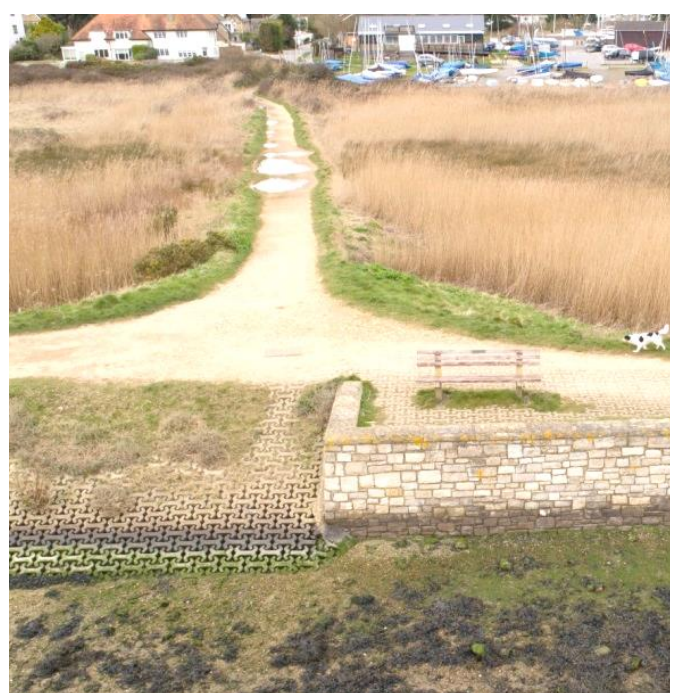

Figure 1. Example of a transition from a concrete block armoured slope to a rock stacked wall on the flood defence line at Hurst Spit on the south coast of England. Source: RHDHV

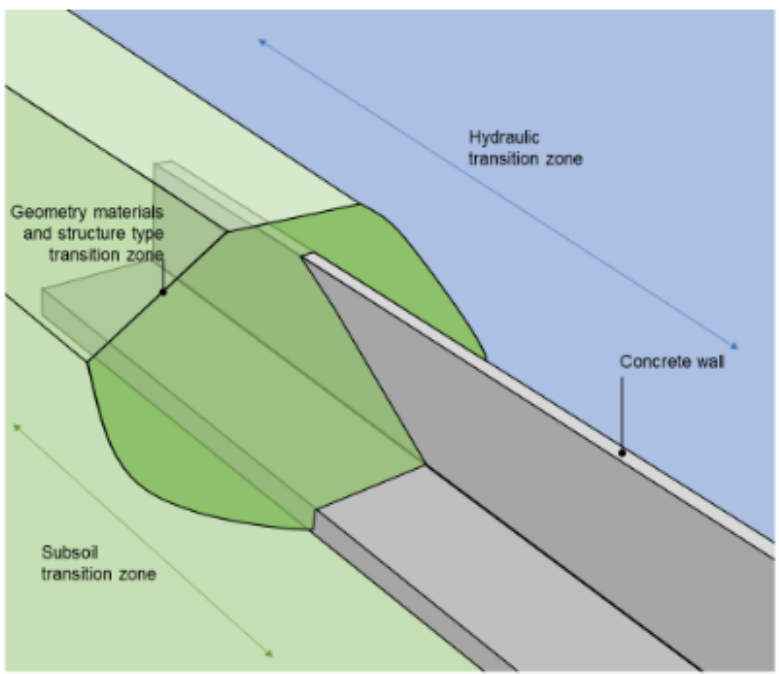

Figure 2. Example transition zone from different perspectives.

The evidence from historical floods is that most levee failures occur around transitions. This is illustrated by well-known cases such as the levee failures in New Orleans during hurricane Katrina (USACE, 2011), and by the findings from reviews of levee performance during UK flood events since 2007 (Simm et al, 2017). This is also demonstrated in full-scale physical model experiments in the field (van Steeg et al, 2015 and Steendam et al, 2014). The fact that transitions often form weak points within a defence system is recognised internationally, and agencies and organisations, particularly within the Netherlands, France and USA, have directed effort to understand how transitions affect overall flood defence performance and how these impacts should be addressed within an overall risk-based approach to their management. Some of this work is reflected in the International Levee Handbook (CIRIA, 2013) and in a manual currently being developed by USACE (2020) related to conduits, pipes and culverts associated with dams and levees.

\section{The research project}

Current guidance in England and Wales on the visual inspection of flood defence assets (Environment Agency, 2012) does not explicitly account for the potential effects of transitions on defence performance and its rate of deterioration. Current risk analysis methods also fail to directly account for the risks arising from transitions. Furthermore, guidance on design detailing and suitable remedial works for transition zones is limited to that provided by the International Levee Handbook (CIRIA, 2013). This research will make a significant contribution towards addressing these omissions. The project has delivered three main products:

1. guidance on the identification, prioritisation, inspection and evaluation of different types of transitions in flood defence systems;

2. a tool that allows the reliability of transitions to be represented as fragility curves (and thus accounted for within risk analyses of flood defence systems); and

3. guidance on the assessment and prioritisation of maintenance activities and remedial works at transitions.

\section{Types of transition considered by the research and their prevalence}

A project workshop held in London in October 2018 provided the opportunity to collect experiences and views from stakeholders involved in asset flood risk management regarding their perceptions of transitions. The stakeholders were mostly from UK but also included representatives from US, France and Netherlands. The feedback identified the most frequent and vulnerable types of transitions to be those:

- between levees and flood walls or hard point assets;

- at culvert and pipeline crossings of levees; and

- between soft and hard revetments.

To support these initial findings, a spatial analysis of the Environment Agency Flood Defence database for England, named AIMS (Asset Information and Maintenance System), was undertaken to secure a highlevel quantitative estimate of the number of possible flood defence to flood defence transitions in England and their type. (Transitions between flood defences and non-flooddefence structures have not been analysed.) The analysis identified 20,709 transitions involving a levee. Of those, $40 \%$ corresponded to transitions between different types of levees, $38 \%$ to transitions between levees and high ground and $22 \%$ to transitions between levees and hard structures. For the $22 \%$ between levees and hard structures (4,506 in total), a further breakdown is summarised in Table 1 and 


\begin{tabular}{|c|c|c|}
\hline $\begin{array}{c}\text { Transition } \\
\text { between levee and }\end{array}$ & Number & $\begin{array}{c}\text { Percentage } \\
(\mathbf{\%})\end{array}$ \\
\hline Wall & 3,362 & 75 \\
\hline Bridge \& abutment & 524 & 12 \\
\hline Culvert & 488 & 11 \\
\hline Flood Gate & 94 & 2 \\
\hline $\begin{array}{c}\text { Demountable } \\
\text { defence }\end{array}$ & 38 & 1 \\
\hline Total & 4,506 & 100 \\
\hline
\end{tabular}

Table 1. Number of transitions between levees and hard flood defence structures

shows that three quarters correspond to transitions with vertical walls.

This combined evidence was used to focus the research project on the study of four specific transition types, listed below and illustrated in Figure 3:

- Type 1 - Longitudinal transitions between embankments and 1) flood walls and 2) point assets (e.g. stairs, flood gates, etc) and between soft and hard embankment revetments;

- Type 2 - Cross-sectional transitions in an embankment with a flood wall above;

- Type 3-Crossing infrastructure

- Type 4-Longitudinal change in revetment type.

\section{Failure mechanisms at transitions}

The possible failure of a transition typically occurs with some form of hydraulic loading and one or more failure mechanisms. The European FLOODsite project produced an initial inventory of failure mechanisms (Allsop et al, 2007). Further developments on the topic of failure mechanisms are also contained in the International Levee Handbook (Chapter 9.11 in CIRIA, 2013) and the ICOLD bulletin on internal erosion (ICOLD, 2016). The main failure mechanisms are described in the sections below.

Initiation of a failure mechanism is likely to be related to one or more of the transition impacts mentioned in the introduction to this paper. These impacts often lead to deterioration which then causes vulnerability to one or more failure mechanisms. Furthermore, the nature and rate of deterioration can become more severe where there is impeded maintenance

\subsection{External Erosion}

External erosion, also called surface erosion, may be caused by:

a) overtopping or overflowing, leading to shear stresses on the landside slope of the earth embankment;

b) wave action on the waterside slope;

c) longitudinal flow acting on the waterside slope;

d) local turbulence due to changes in geometry (or geometry irregularities) or roughness across two materials on the waterside slope.

At transitions these actions can be larger due to changes in geometry or lower crest elevations of one of the asset. Furthermore, at transitions there can also be a strength reduction, for example where there is weaker grass due to various transition impacts.

\subsection{Internal erosion}

Internal erosion involves the detachment of soil particles and their transport by seepage flow. There are four main internal erosion mechanisms (Morris et al, 2012, ICOLD, 2016, Tourment, 2015):

a) Contact erosion: related to selective erosion of fine particles from the contact with a coarser layer;

b) Backwards erosion: occurring along a decompressed contact area as a result of seepage exiting an unfiltered surface; it leads to retrogressively growing soil piping and sand boils;

\begin{tabular}{|c|c|c|c|}
\hline Longitudinal transitions & $\begin{array}{c}\text { Cross-sectional } \\
\text { transitions }\end{array}$ & Crossing infrastructure & Revetments \\
\hline Type 1 & Type 2 & Type 3 & Type 4 \\
\hline $\begin{array}{c}\text { Between embankment and } \\
\text { flood wall }\end{array}$ & $\begin{array}{c}\text { Between embankment and } \\
\text { crest wall }\end{array}$ & $\begin{array}{c}\text { Between embankment and } \\
\text { crossing structure }\end{array}$ & $\begin{array}{c}\text { Between soft and hard } \\
\text { revetments }\end{array}$ \\
\hline $\begin{array}{c}\text { Between embankment and } \\
\text { point asset }\end{array}$ & $\begin{array}{c}\text { Between toe wall and } \\
\text { embankment }\end{array}$ & & \\
\hline
\end{tabular}

Figure 3. The four types of transition considered. 
c) Concentrated leak erosion: related to the detachment of soil particles through a pre-existing path, such as a crack - given the largely clay composition of most UK flood embankments, this mechanism is believed to be the most important transverse internal erosion process for transitions between soil and hard structures;

d) Suffusion: related to the selective erosion of the fine particles from a matrix of coarse particles.

The process of internal erosion can broadly be broken into four phases: initiation, continuation, progression to form an erosion piping zone (causing surface sloughing) and initiation of a breach. It can include one or more of the four internal erosion mechanisms (Morris et al, 2012).

Transitions can potentially be zones of preferred seepage paths and where erosion can be initiated and develop. Hydraulic gradient across the structure, the driving loading factor causing seepage, may also be increased at transitions due to changes in geometry. Leakage from or into an embedded pipeline can also be a cause of internal erosion at the transition between pipeline and embankment (Further discussion of pipeline transitions can be found in an upcoming USACE (2020) Engineering Manual).

\subsection{Slope and mass instabilities}

Slope instability includes sliding and collapsing while mass instability includes settlement due to soil disturbance or poor compaction and liquefaction.

Instabilities may occur as a result of hydraulic gradient or uplift forces which could have larger impacts at transitions due to internal (and thus largely invisible) changes in permeability, poor compaction or poor soil properties. More visible scour at the toe of a structure can also cause slope instability.

\subsection{Hard structure instability}

Hard structure (flood wall) instability is related to the collapse (due to undermining of support material), overturning or sliding of the structure. This can be caused by the increase of external erosion processes at a transition due to changes in geometry (scour at the toe), subsidence caused by different assets settlement or due to increase of hydraulic impact forces caused by changes in geometry. In the research, although the designer still needs to consider this possibility, it was decided not to pursue this mechanism for the reliability analysis since it is largely a matter of the design of composite structures- see Section 7. (Failures, such as that of the I-walls in New Orleans which are highly dependent on lateral support from the earthen levee, are rare in the UK.)

\subsection{Crest degradation}

The loss of crest elevation can cause the functional or hydraulic failure of the flood defence system. At transitions, rutting or a difference in crest elevations between a levee and flood wall, can create preferential overflow paths. This in turn may exacerbate problems of external erosion of the rear face (see Section 4.1 above).

\section{Transition risk management process}

The transition asset risk management process can be considered to comprise 5 steps:

- Step 1: Identification of transitions that may cause a weak point (reducing strength or increasing loading)

- Step 2: Prioritisation of transitions for improvement based on performance and risk assessment.

- Step 3: Design of the improvement.

- Step 4: Implementation.

- Step 5: Operation and maintenance

Each of the three key products of the research described in this paper are related to one of the first three steps:

- The inspection and assessment guidance for transitions relates to Step 1 .

- The processes for evaluation of transition reliability/vulnerability relates to Step 2

- The guidance on the design of remedial works for transitions relates to Step 3 .

The development of each of the three products is described in the following sections of this paper.

\section{Inspection and assessment of transitions}

Asset inspection is a key part of the overall cycle of risk and performance-based asset management. Inspections are targeted to need rather than being dictated by routine alone, and they allow interventions to be timed to pre-empt asset deterioration and possible failure. Assets are typically identified and recorded in databases, but to date these databases rarely separately identify transitions between flood defence assets or the multiple transitions that may arise in composite assets; this problem is further compounded by additional transitions between flood defence and non-flood-defence assets.

The normal defence asset inspection and evaluation process in the UK is graduated. The default level is routine visual inspection, the procedures for which are well embedded in the Environment Agency using the Condition Assessment Manual (CAM) (Environment Agency, 2012). This is followed, if needed, by other levels of activities which seek more detailed information than is routinely collected. In the first instance a second level of nonintrusive investigations is carried out by an appropriate expert. This may be followed by a third level of intrusive investigations into the make-up of the asset. Both second and third level investigations require additional investment and need to be justified in terms of avoidance of loss of existing risk reduction benefit.

Previous research (see Bown et al, 2014) has identified that these well-established methods do not explicitly highlight issues at transitions, particularly where the transition is at the end of a long linear asset which itself 


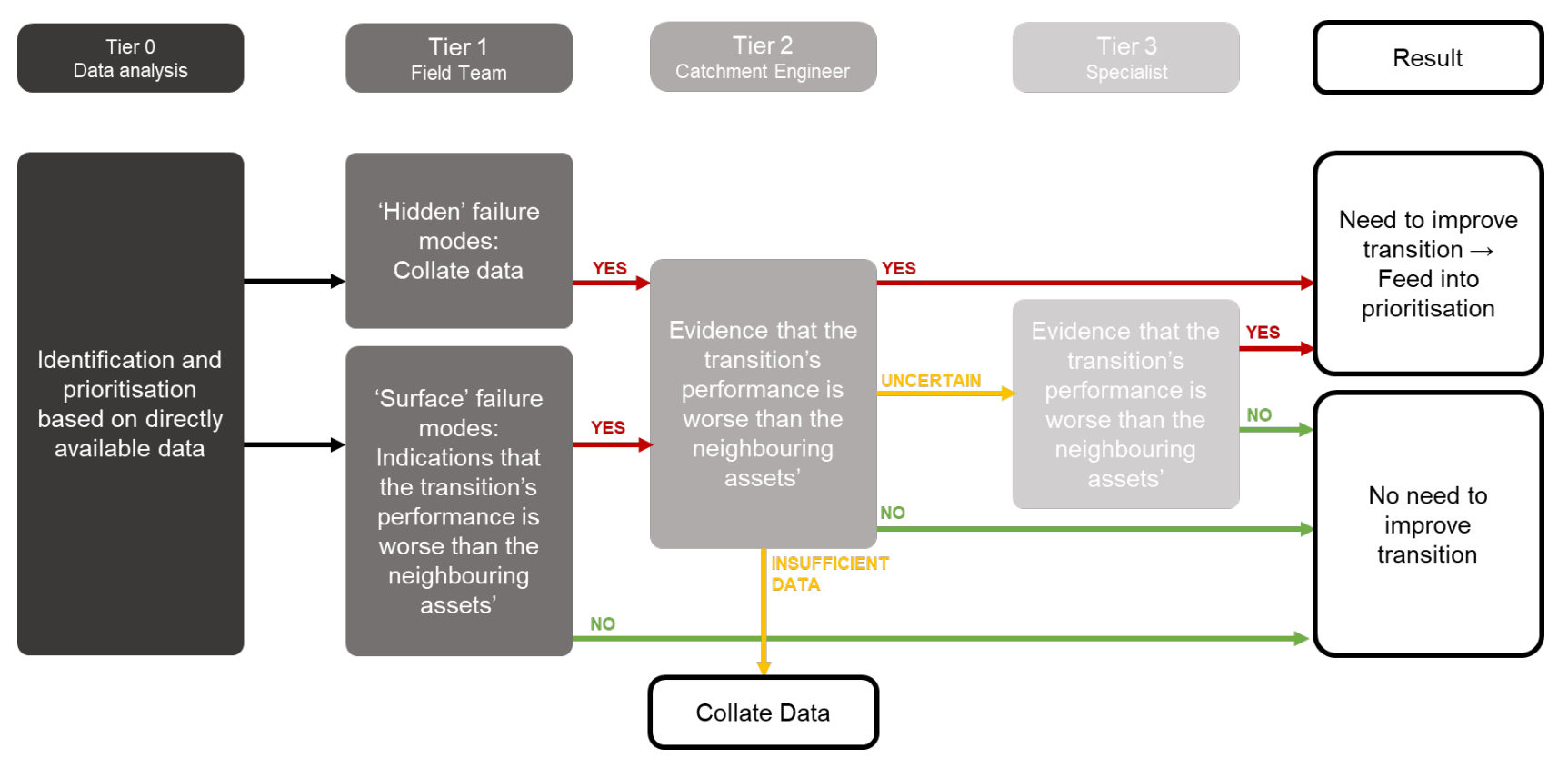

Figure 4. Transitions assessment process

might be in good condition. A Guide has therefore been developed as part of this project to address this gap. This sets out a process that uses available data, field inspection and engineering judgement to determine whether a transition is weaker than the neighbouring defences.

The envisaged users of the guidance are the teams responsible for inspecting assets, evaluating asset condition, and identifying the need for asset improvement. The method of assessment and any recommended improvement methods will depend on the type of transition (see Figure 3). The four types of transition considered in this research) and on the failure mechanisms/modes being considered. The Guide follows (see Figure 4) a bespoke tiered process with each tier described in a separate section and targeted at a specific user:

Tier 0, Prioritisation of asset transitions, is an automated method for initial prioritisation of transition elements for inspection based on how transition impacts are likely to affect defence performance and risk. The identification of assets that require inspection through the Tier 0 process is currently only available for use with the Environment Agency's Asset Information Management System; other organisations need to apply their own prioritisation process to identify the transitions that require to be inspected.

Tier 1, Inspection by field team, is the site inspection stage which is being undertaken by field teams. Flowcharts (see Figure 5 for example) assist the site inspectors to collate the required site information. For more visible failure modes and transition impacts (such as surface erosion) the field inspection may rule out that the transition is causing a weakness. For hidden failure modes (such as seepage and piping) the role of the Tier 1 is to collate local data that can support the Tier 2 engineering assessment.

Tier 2, Assessment by a senior engineer (such as a Catchment Engineer at the Environment Agency), is aided by its own set of flowcharts and uses the information collated during the Tier 1 inspection in combination with other data inputs (such as as-built records, topographic survey etc.). The assessment can lead to one of four results:

- No improvement is needed

- Further information is required to conclude the Tier 2 Assessment (collate data)

- Monitoring is required to determine whether the rate of deterioration has reached equilibrium or is still increasing (collate data)

- Improvement is needed (with or without more advanced Tier 3 assessment)

Tier 3, Assessment by a specialist, would be needed if there is too much uncertainty at Tier 2 (and if the defence is critical enough to warrant the investment).

The flowcharts for Tiers 1-3 are structured by transition type and failure mode combinations. In practice this only leads to a limited set of charts, because (and combined where the transition impacts of the combinations are the same).

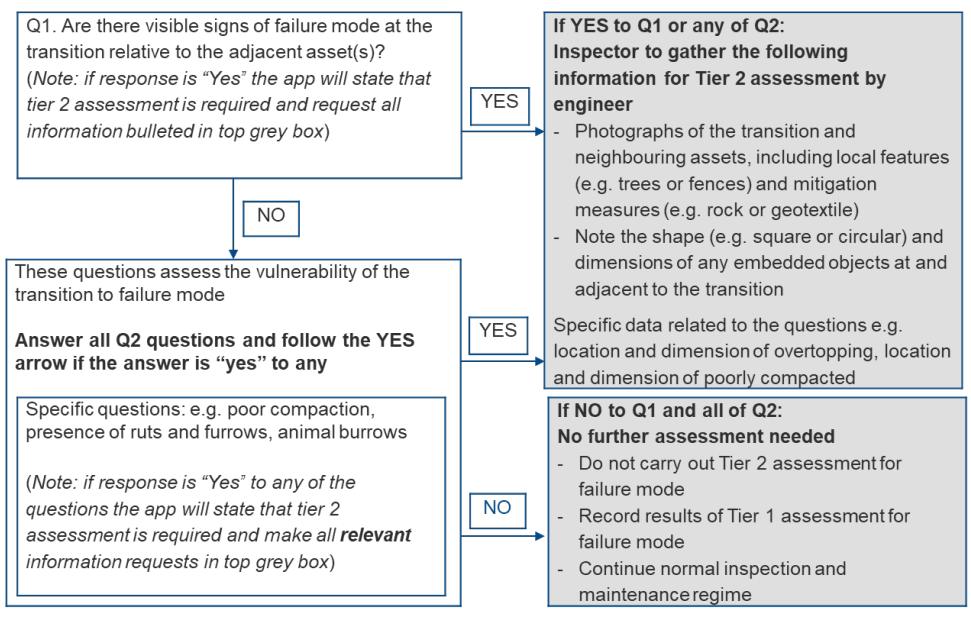

Figure 5. Overall set-up of Tier 1 flowcharts 


\subsection{Pilot testing of approach}

To validate the proposed approach, the flowcharts were piloted with Environment Agency staff on two occasions: in September 2019 on defence transitions on the banks of the River Mersey in Didsbury, Greater Manchester and Warrington and in October 2020 on the Tidal River Trent between Keadby Bridge (Scunthorpe) and Torksey Lock.

Lessons learnt included the following:

1. The global instability, piping/seepage and backfill washout failure mechanisms are difficult to inspect on site.

2. The surface erosion and crest degradation failure mechanisms are visual on site and can be robustly evaluated.

3. Site inspectors should be encouraged to evaluate the entire area associated with the transition including front slope, crest and back slope and think about a 'what if...' scenario (i.e. what might happen to this structure if it were subject to extreme loading or if it were to overtop?).

4. The integration of the transition inspection flowchart logic into existing asset inspection processes for on-site digital recording of information would significantly improve the efficiency and effectiveness of approach. (The second pilot was able to test the incorporation of the transition flowchart logic into an early version of new Environment Agency Asset Information Management System (AIMS) app.)

5. To limit the number of potential transitions to be evaluated, a pre-screening stage (Tier 0) was required to identify transitions likely to pose the greatest risk. A Tier 0 assessment was tested on the second pilot, but because of data limitations (a) captured a number of apparent pipe crossings which in fact lay well beneath the levee and (b) was not able to capture transitions with third party assets (see Figure 6).

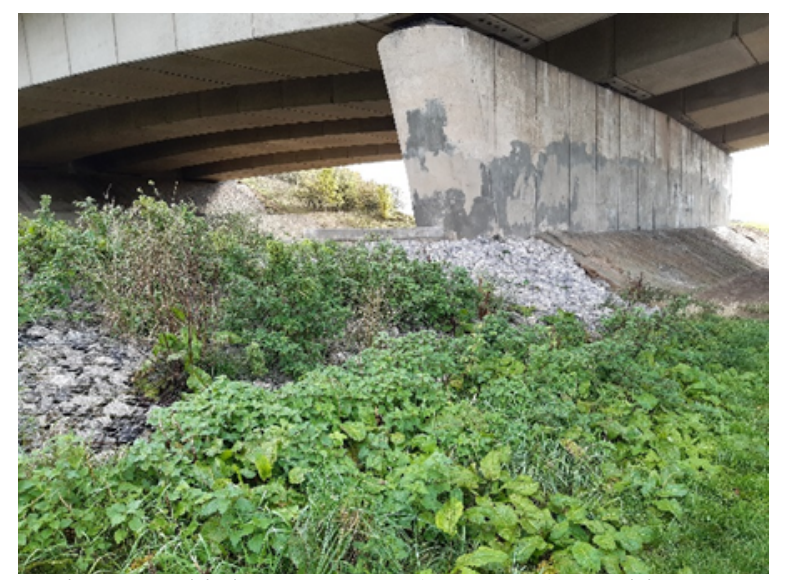

Figure 6. Third party Type 4 (revetment) transition not identified in Tier 0 assessment

6. Maintenance regimes at the interface between hard and soft surfaces may themselves pose a risk to the performance of the transition. An example (see Figure 7) is grass control adjacent to walls undertaken by weed spraying to avoid the adverse hand-arm vibration health effects of repeated use of strimmers.

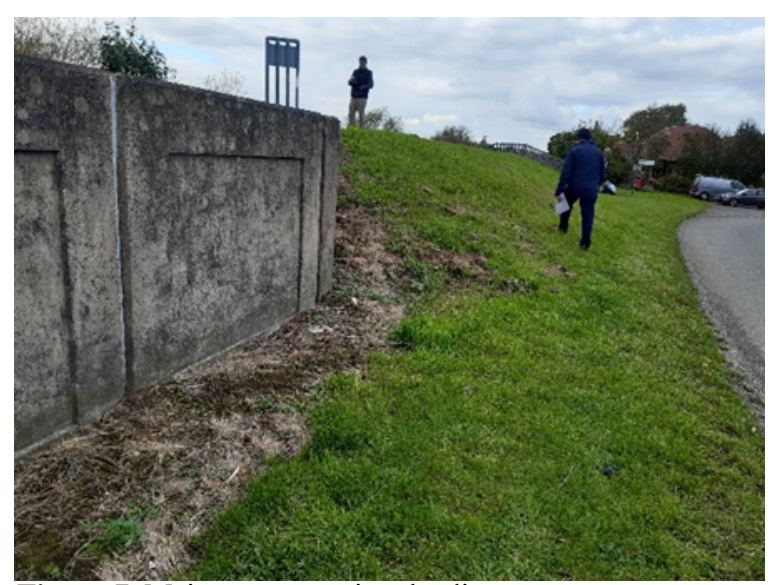

Figure 7. Maintenance regime leading to poor grass cover.

7. Structural detailing such as settlement allowances for earthen levees or fences introduced for public safety may encourage preferential flow paths or animal/human rutting.

\section{Evaluating transition vulnerability}

\subsection{Limit state equations and fragility curves}

In order to evaluate the impact of transitions on levee performance (see Introduction for list of transition impacts), an existing reliability analysis tool (hrRELIABLE) has been further developed to permit the creation of fragility curves for the most important types of transition.

Fragility curves (Simm, 2008; Simm \& Tarrant, 2018) represent the probability of failure of a flood defence given a particular hydraulic load (e.g. water level). Curves can be generated from one or a combination of Limit State Equations (LSEs) by expressing them in reliability format: where:

$$
z=F(R)-G(S)
$$

$\mathrm{F}(\mathrm{R})$ is a function of a defence ability to resist a specific mechanism relatively to a certain type of load, and

$\mathrm{G}(\mathrm{S})$ is a function of the load that is being applied to the defence on a specific event.

Once in this form the likely performance of an asset can be assessed as a probability of failure against a full range of loading conditions. As the true performance of the asset is likely to be unknown, the inputs to the model are varied according to a distribution chosen for each variable. By performing a large number of evaluations for each load, and keeping track of the proportion of "fail" results to "non-fail" results, the fragility curve takes shape for a given load X-axis.

Fragility curves are useful in three ways:

a) to help better understand the performance of a transition;

b) as inputs into the risk analysis of flood defence systems.; and 
c) as a means (when combined with known loading distributions for prioritising transitions for assessment)

In the latter case fragility curves are used to represent the performance of defence segments as part of the Pathway component of a Source - Pathway - Receptor analysis (Gouldby et al, 2008).

In order for the LSEs to generate appropriate fragility curves, it is essential that (i) the correct LSEs are selected, (ii) meaningful inputs are chosen for those LSEs and an appropriate distribution identified for those inputs. We address each of these points in turn:

When selecting LSEs for levee transitions, we focussed on

- concentrated leak erosion as the internal erosion mechanism (see ICOLD 2016a and 2016b) as this best represents both (a) the hydraulic separation issues that arise at the interface between hard materials and earthen structures and (b) the common issues with animal burrowing in UK levees which lead to the potential for focussed flow paths through the levees

- landward face external/surface erosion of grass covered slopes

Mechanisms not evaluated were the following:

- slope instability (also called mass instability), since (a) this mechanism is rare post construction in the UK, especially for landward slopes of levees since hydrographs are generally too short to elevate pore pressures sufficiently (b) failures of waterward slopes tend either to occur after floods due to rapid drawdown

- external erosion of the waterward levee slope due to incision of banks on the outside of river bends which may then lead to mass instability since this is specific to the exact geometric arrangements;

- instability of hard structures within a composite defence involving an earthen levee since the instability is more a matter of the design of the composite structure than of the transitions as such (see discussion in Section 4 above.)

When identifying input value ranges for the selected mechanisms, our focus was on ensuring the correct geometry for the different transition types or on otherwise modifying the input parameter values for the two main LSEs, either increasing the loading or reducing the strength.

Given the focus on these two mechanisms, the relevant mechanism for water levels below embankment crest level was concentrated leak erosion only. For water levels above embankment crest level, the failure mechanism will be a combination of internal and external erosion processes. Where appropriate, the fragility curves for each of these processes are combined using De Morgan's Law (as explained in Simm et al, 2008)

Of the four transition types addressed by the research the focus for reliability analysis was on Types 1, 3 and 4 (see Section 4 above for description). As mentioned earlier, Type 2 transitions were not evaluated because they are associated with composite structures and the focus is either on the whole structure (e.g. overall instability) and or on a myriad of interfaces associated with the multiplicity of potential combinations of hard and soft elements in a composite structure which did not readily lend itself to analysis.

The selected LSEs have all been implemented in a software tool (hrRELIABLE) which generates fragility curves.

\subsection{The representation of concentrated leak erosion at transitions}

Concentrated Leak Erosion is only relevant for Transition types which pass through (the majority of) the embankment structure: Types 1 (embankment to wall) and 3 (embedded object). The initiation of a concentrated leak failure at transition assets has been modelled using the following reliability equation:

where:

$$
z=\tau_{\mathrm{c}}-\tau
$$

$\tau$ is the applied hydraulic shear stress (N/m2) calculated based on hydraulic load and crack type and length.

$\tau_{\mathrm{c}}$ is the critical shear stress $(\mathrm{N} / \mathrm{m} 2)$ determined based on soil type and erodibility.

Hydraulic shear stress is determined using the following equation from the ICOLD bulletin 164, assuming a vertical, transverse crack shape:

Where:

$$
\tau=\frac{\rho_{w} g H_{f}^{2} W}{2\left(H_{f}+W\right) L}
$$

$\rho_{\mathrm{w}} \quad=$ Density of water $(\mathrm{kg} / \mathrm{m} 3)$

$\mathrm{g}=$ Acceleration due to gravity $=9.8 \mathrm{~ms}^{-2}$

$H_{\mathrm{f}} \quad=$ Head loss $(\mathrm{m})$ in pipe or crack due to friction

$L \quad=$ Length $(\mathrm{m})$ of pipe or crack base

$D \quad=$ Diameter $(\mathrm{m})$ of the pipe

$W \quad=$ Width (m) of crack

Following sensitivity testing of the impact of different crack widths, a constant $2 \mathrm{~mm}$ crack width was adopted. Crack length is based on the geometric characteristics of the transition, using a triangular distribution to define most likely, minimum and maximum lengths - to account for the uncertainty in this assumption. The assumed crack length is automatically adjusted based on the condition of the adjacent embankment asset. It has been assumed that visual inspection cannot identify any increased risk of internal erosion, therefore no further adjustments are proposed for LSE parameters. Head losses are based on assumed differences in water level across an assumed crack elevation.

Critical sheer stress is dependent on the relative erosion rate index associated with the soil type present at the transition. ICOLD (2016a) provide representative Erosion Rate Indices $I_{\mathrm{HET}}$ for both dispersive and nondispersive soils, which are considered to be a reasonable assumption for a designed flood defence transition asset. The ICOLD bulletin associates these erosion rate indices with critical shear stress values. The limits and best values for the distributions of sheer stress associated with the $I_{\mathrm{HET}}$ values for non-dispersive soils adopted in the research are provided in Table 2 . 


\begin{tabular}{|c|c|c|c|}
\hline $\boldsymbol{I}_{\text {HET }}$ & Low & Best & High \\
\hline Up to 3 & 1 & 2 & 5 \\
\hline 3.5 & 2 & 5 & 25 \\
\hline 4 & 5 & 25 & 60 \\
\hline 5 & 25 & 60 & 100 \\
\hline
\end{tabular}

Table 2. Limits and best estimates for a triangular distribution of critical shear stress for different non-dispersive soil types

\subsection{The representation of external/surface grass erosion at transitions}

The initiation of external erosion at transition assets has been modelled using the following reliability equation:

$$
z=\alpha^{\mathrm{s}} q \mathrm{c}-\alpha_{\mathrm{M}} \alpha_{\mathrm{a}} q_{\mathrm{a}}
$$

where:

$q_{\mathrm{c}}$ is critical overtopping rate $(\mathrm{m} 3 / \mathrm{s} / \mathrm{m})$

$q_{\text {a }}$ is actual overtopping rate $(\mathrm{m} 3 / \mathrm{s} / \mathrm{m})$

$\alpha_{\mathrm{M}}$ is the load factor

$\alpha_{\mathrm{s}}$ is the strength factor

$\alpha_{\mathrm{a}}$ is the acceleration factor

Critical overtopping rate is calculated using the Vrouwenvelder et al (2001) method, which is a parameterisation of the CIRIA 116 (Hewlett et al, 1987) curves, with adjusted coefficients to reflect the original data on which those curves were based (Whitehead \& Nickersons, 1976). The assumed erosion resistance of the grassed clay surface is a key component of the method and this is adjusted based on the difference between the general condition of the adjacent levee and the condition immediately at the transition. Actual overtopping rate is calculated based on the embankment geometry and water level conditions (as for levees generally).

Values for the various factors are taken from two sources.

For Type 1 transitions, the factors are taken from computational fluid dynamic (CFD) modelling specifically carried out for this research (see Section 7.4) that indicated the likely increases in velocity and shear stress at embankment-wall transition points

The resultant overall velocity amplification factors adopted for Type 1 transitions are given in Table 3. The acceleration factor has been set at 1.0 since flow accelerations are already included in the way that the velocities are calculated.

\section{Levees with steeper slopes (1:1 to 1:1.9)}

\begin{tabular}{|c|c|c|c|}
\hline $\begin{array}{c}\text { Transition } \\
\text { configuration }\end{array}$ & Low & Best & High \\
\hline $\begin{array}{c}\text { Levee lower than } \\
\text { adjacent flood wall }\end{array}$ & 1.00 & 1.14 & 1.26 \\
\hline $\begin{array}{c}\text { Levee higher than } \\
\text { adjacent flood wall }\end{array}$ & 1.10 & 1.26 & 1.41 \\
\hline $\begin{array}{c}\text { Levee and wall of } \\
\text { equal height }\end{array}$ & 1.00 & 1.14 & 1.26 \\
\hline
\end{tabular}

Levees with shallower slopes (1:2 or shallower)

\begin{tabular}{|c|c|c|c|}
\hline & \multicolumn{3}{|c|}{ Velocity amplification factor } \\
\hline $\begin{array}{c}\text { Transition } \\
\text { configuration }\end{array}$ & Low & Best & High \\
\hline All & 1.00 & 1.18 & 1.34 \\
\hline
\end{tabular}

Table 3. Velocity amplification factors for Type 1 (levee/wall) transitions
For Type 3 and Type 4 situations, the factors are taken from research carried out for wave dominated situations (van Bergeijk, 2018, Verheij et al, 2013 and van Hoven, 2015) which provide results from (unsteady) wave overtopping experiments, rather than steady overflow situations relevant to fluvial situations. The justification for assuming transferability to the fluvial situation is that factors relate to modifications of force or pressure rather than relating to flow rates or velocities. It is acknowledged that it is not ideal that the pressures in the unsteady situation are pulsating whereas in the fluvial case they will be steadier, but in the absence of other research to draw on, they are a good starting point until further testing and validation is available. Uncertainty in the factors adopted for use in the LSEs is also accounted for within the hrRELIABLE tools by using a triangular distribution rather than a single value for the factors.

Verheij et al (2013) and van Hoven (2015) proposed the use of the following equations to quantify the increase in loads:

For upstream effects: $\alpha_{\mathrm{m}}=1+\mathrm{C}_{\mathrm{d}} / 4$

For side effects: $\alpha_{\mathrm{m}}=1.4 \mathrm{~K}_{\mathrm{s}}$

where

$\mathrm{C}_{\mathrm{d}}=$ the drag coefficient and

$\mathrm{K}_{\mathrm{s}}=$ the shape factor.

These factors are defined by Verheij et al (2013) and van Hoven (2015) based on the 'flow impact' shape at the transition point. Since the reliability equations are based on velocity rather than shear stress (proportional to the square of velocity), all factors are again implemented as the square root of the loading/resistance factors. The resultant velocity amplification factors adopted are given in Table 4.

\begin{tabular}{|c|c|c|c|}
\hline & \multicolumn{3}{|c|}{ Amplification factor } \\
\hline $\begin{array}{c}\text { Transition } \\
\text { configuration }\end{array}$ & Low & Best & High \\
\hline $\begin{array}{c}\text { Type 3 and Type } 4 \\
\text { transition shear } \\
\text { stress factors }\end{array}$ & 1.00 & 1.50 & 1.70 \\
\hline $\begin{array}{c}\text { Type 3 and Type } 4 \\
\text { transition velocity } \\
\text { factors }\end{array}$ & 1.00 & 1.23 & 1.30 \\
\hline
\end{tabular}

Table 4. Amplification factors for Type 3 and Type 4 transitions

\subsection{Investigation of increased loading forces at levee to wall using computational fluid dynamic (CFD) modelling}

A CFD model of a typical channel was built in order to assess the hydrodynamic performance of the overflow at the transition between a levee (grass embankment) and a flood wall (vertical wall). The objectives of this supporting study were to assess the relative increase of flow velocities and shear stresses at these transitions, with particular interest in the grassed levee, which is the "weaker" structure.

The CFD simulations were performed using the OpenFOAM ${ }^{\circledR}$ software package (www.openfoam.com. Four alternative transition geometries were represented within a single CFD model as indicated in Figure 7. The 
geometry allowed examination of transitions between two different types of flood defences, i) a flood wall $30 \mathrm{~cm}$ thick and ii) embankments with crown width of $1 \mathrm{~m}$ and slopes of $1 \mathrm{~V}: 1.5 \mathrm{H}$ and $1 \mathrm{~V}: 2.5 \mathrm{H}$. The transitions included crest height differences and the lower section was set to be lower than the main river water level, thus allowing an overflow discharge to develop. The main river flow was assumed to have an average velocity of $1.5 \mathrm{~m} / \mathrm{s}$ running under a downstream slope of $0.1 \%$.

The CFD study provided the following learning to the project:

- A qualitative description of flow velocity patterns how it is influenced by the presence of transitions between a grass embankment and a vertical wall.

- A quantitative estimation of the change in flow velocities due to the presence of transitions.

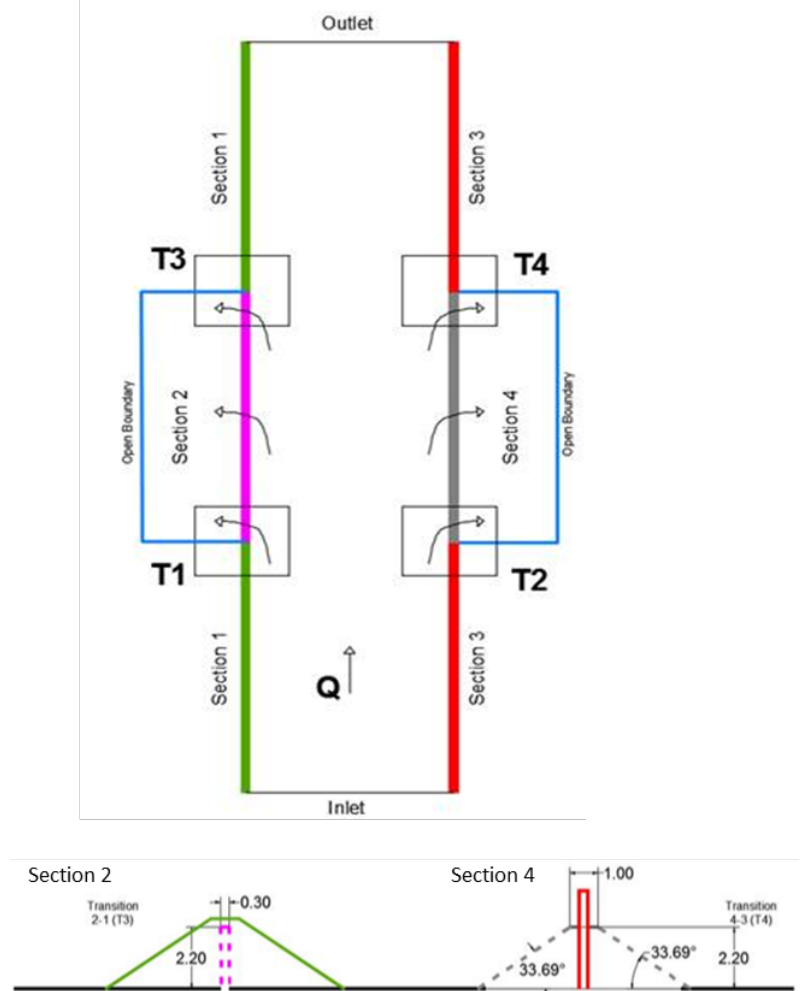

Figure 7. Configuration of levees and floodwalls investigated to examine loading forces at transitions using computational fluid dynamic (CFD) modelling

- A quantitative estimation of the change in shear stress above the rear side of the grass embankment.

Results were presented in terms of velocity amplifications and shear stress amplifications. The amplification of the shear stress at the transitions was calculated in comparison with the level of shear stresses at main trunk of the overflowed structure (the reference section). Model results (see e.g. Figure 8) suggest that there is an amplification factor on shear stress of up to 1.6.

\subsection{Sensitivity analysis}

A sensitivity testing exercise was undertaken looking at the impact of a range of asset and hydraulic loading characteristics on the fragility (failure vulnerability) of a particular transition.

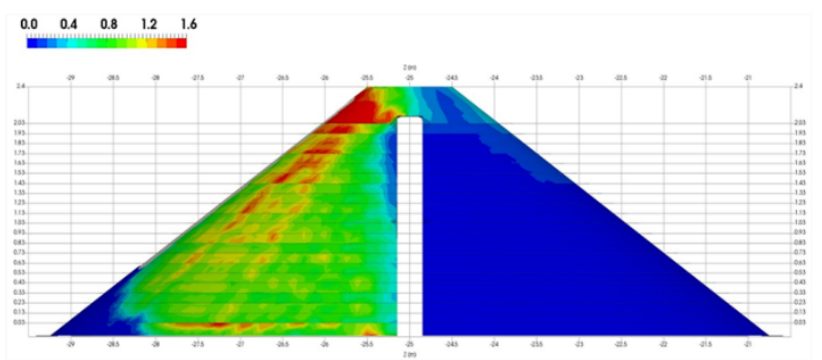

Figure 8. Example shear stress amplification factors from the CFD modelling study

The objectives of the testing were to:

- Explore the sensitivity of the annual failure probability to a number of parameters (e.g. geometry, soils) using a generic hydraulic loading condition; and,

- Evaluate the impact of a range of plausible hydraulic loading conditions on the outcomes.

The sensitivity analysis used the following procedure: (1) generate the fragility curve relevant to each test; then (2) calculate for each fragility curve a single number, the annual failure probability by integrating the fragility curve with the distribution of extreme loadings at the site in question. This annual failure probability is determined as the sum of $(\mathrm{P}(\mathrm{F})$ given load from fragility curve $\mathrm{x}$ load probability) across all loads.

The sensitivity analysis was conducted in two stages: Stage 1 sensitivity analysis. The first stage focussed on the pilot site at the Tidal Trent. This stage examined the effect of varying each of the input parameters into the LSEs (Limit State Equations) used to generate the fragility curves. These input parameters represented the properties of the transition, either related to the strength of the transition itself or of the adjacent embankment. For this stage, for the purposes of determining the annual failure probability associated with each curve, a single loading distribution representative of the Tidal Trent was used. From this first stage analysis, the following aspects of the earthen levees associated with transitions were identified as being the most influential on reliability:

- levees with heights greater than or equal to 2 metres,

- levees with slopes of 1:3 or steeper

- levees with crest widths of $4 \mathrm{~m}$ or less

Stage 2 sensitivity analysis across all England. Varying only those input parameters into the fragility curves having the most impact, the analysis was re-run for all transitions in England using a database of 22,919 transitions supplied by the Environment Agency, complemented by loading distribution data available from the State of the Nation analysis. Examining the data there was no general relationship between the loading distribution and the height of the defence at each transition (crest level minus ground level on the landward side of the defence). The procedure adopted therefore was as follows:

a. generate fragility curves for embankments of a range of heights and slopes incrementing in $0.1 \mathrm{~m}$ intervals of height from 0 to $6 \mathrm{~m}$. 
b. for each of the 22,919 locations, select the fragility curve most appropriate to the height and slope of the defence (all potential slopes were examined at each location).

c. Generate the annual failure probability by combining the selected fragility curve with the loading distribution relevant to that location.

This comprehensive analysis of nearly 24,000 assets focussed on finding situations where at least $99 \%$ of the annual failure probabilities are less than 5\% (0.05). (5\% is typically taken as a reasonable maximum allowable annual failure probability.) The results suggested a very significant number of transition assets could be excluded from evaluation and that the focus should be on situations where the earthen levee at the transition:

- for side slopes 1:1.5, had height greater than $1.75 \mathrm{~m}$;

- for side slopes 1:2, had height greater than $2.0 \mathrm{~m}$ :

- for side slopes 1:3, had height greater than $3.0 \mathrm{~m}$

- for side slopes 1:4, had height greater than $4.0 \mathrm{~m}$

- for side slopes 1:5, had height greater than $5.0 \mathrm{~m}$

This more comprehensive analysis supported the Stage 1 conclusion that only transition assets with earthen levee heights (crest level minus landward ground level) greater than or equal to 2 metres need be prioritised for inspection and investigation. This simplified conclusion is cautious, but does reflect the considerable uncertainty about the actual side slopes of many of English embankments.

\section{Addressing transition impacts and remedial design}

\subsection{Introduction}

The transition design guide supports the design of improvements to flood defence transitions with a view to reducing their vulnerability. The place of improvement in the asset management process is described in Section X.

The envisaged use of the transitions design guide starts from the outcome of Step 2 (the Tier $2 / 3$ Assessment) and the transition impact that causes a weak link. The guide is intended for the design of improvements to existing transitions, with the aim of achieving a situation where the transition is no longer the weakest point.

\subsection{Application of the transition design guide}

The concept and listing of the main transition impacts was described in the introduction to this paper. Understanding the transition impacts is essential for not only identifying weaknesses but also for remediating them.

Table 5 shows for each transition impact the failure mechanisms that it can cause. Those shown in the Table 5 are directly initiated mechanisms, but these can typically then trigger other failure mechanisms; such secondary effects are not shown in this table). Green cells concern a reduction in strength, orange cells an increase in loading. Table 5 also shows the transition types to which each transition impact is most likely to apply. Note that this table may not be exhaustive.

\begin{tabular}{|c|c|c|c|c|}
\hline & \multicolumn{4}{|c|}{ Transition Type (see Figure 3) } \\
\hline Transition Impact & 1 & 2 & 3 & 4 \\
\hline \multicolumn{5}{|l|}{ 1) Geometry } \\
\hline Shorter seepage paths & SP & & & \\
\hline Steeper slope angles & SI, SE & & & \\
\hline $\begin{array}{l}\text { Irregular geometry } \\
\text { causing turbulence }\end{array}$ & SE & SE & $\mathrm{SE}$ & SE \\
\hline \multicolumn{5}{|l|}{$\begin{array}{l}\text { 2) Difference in } \\
\text { materials behaviour }\end{array}$} \\
\hline $\begin{array}{l}\text { Hydraulic separation } \\
\text { and strain } \\
\text { incompatibility along } \\
\text { hard/soft interfaces }\end{array}$ & SI, SP & SP & SI, SP & \\
\hline $\begin{array}{l}\text { Impeded grass root } \\
\text { formation and shading }\end{array}$ & SE & SE & & SE \\
\hline Gaps in filter structure & & & & BW \\
\hline \multicolumn{5}{|l|}{$\begin{array}{l}\text { 3) Impediments to } \\
\text { construction and } \\
\text { maintenance }\end{array}$} \\
\hline Poor compaction & SI, SP & & SI, SP, SE & \\
\hline $\begin{array}{l}\text { Poor maintenance due } \\
\text { to poor access and } \\
\text { visibility }\end{array}$ & & & & SE \\
\hline \multicolumn{5}{|l|}{$\begin{array}{l}\text { 4) Preferential paths } \\
\text { for humans or } \\
\text { animals leading to } \\
\text { deterioration }\end{array}$} \\
\hline $\begin{array}{l}\text { Surface rutting } \\
\text { (vehicles, pedestrians, } \\
\text { animals) }\end{array}$ & $\mathrm{CH}, \mathrm{SE}$ & SE & & \\
\hline Animal burrows & $\mathrm{CH}, \mathrm{SE}$ & & & \\
\hline
\end{tabular}

Key: SI = Slope instability; SP $=$ Seepage and Piping; $\widehat{\mathrm{BW}}=$ Backfill Washout; $\mathrm{CH}=$ Crest Height degradation; $\mathrm{SE}=$ Surface Erosion

Table 5. Transition impacts and failure modes for each transition type

For each of the identified transition impacts the design guide describes and illustrates the physical process, the relation with failure mechanisms, principles for design, improvement methods, design approach and examples.

\subsection{Design guide users}

The envisaged users of the design guide are the teams responsible for designing flood defence improvements, in particular senior engineers, in any flood defence asset management organisation. In the specific context of the Environment Agency, this would be the Catchment Engineers, the Asset Performance Teams, the Operational field teams and potentially their consultants as well.

\subsection{Principles for managing transitions}

The design guide introduces the following 12 principles for managing transitions. Principle 1-4 were already introduced for transitions in CIRIA (2013); principles 5-12 were added through the development of the design guide. 
1. Take care in the detailing

2. Range of loading scenarios

3. Consider all relevant hydraulic loading

4. Consider deterioration

5. Avoid transitions altogether if possible

6. Make sure the transition is not the weakest link

7. Err on the side of caution

8. Transitions should be gradual

9. Improvements can introduce new transitions

10. Improvements can create other impacts

11. If design standards cannot be met, then manage the associated risks.

12. Manage any short-term performance reduction

\subsection{Improvement methods: transition methods vs regular non-transition methods}

The guide focuses on the improvement of transitions. In many instances, the improvement methods and design approaches are strongly linked to, and very similar to those for regular flood defence embankments and structures. The transition design guide does not provide a step by step process with detailed instructions for addressing transition impacts. Instead it focuses on the principles (how can transitions influence performance), highlights the issues with managing transitions, and presents methods for addressing the impacts. The design methods are typically not discussed in detail, because these are often very similar to methods for design and management of flood defences in general. The intention throughout is that the guide is used alongside the existing guidance and standards, notably CIRIA (2013).

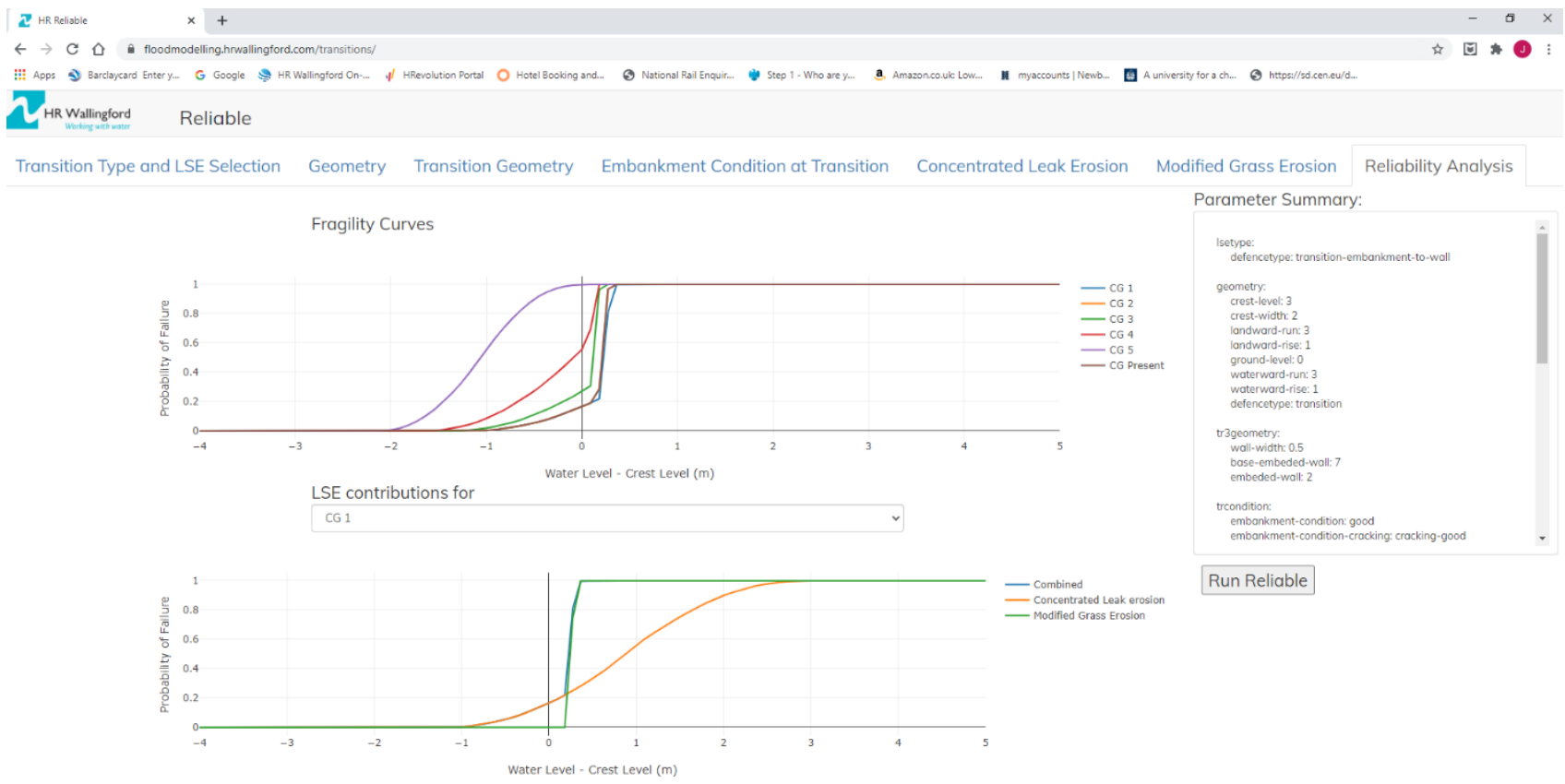

Figure 9 Web interface for hrRELIABLE fragility curve generation tool for transitions

\section{What's next / roll out}

The Environment Agency has incorporated the transition inspection module into the AIMS App (which covers the usual asset inspection). This tool in combination with the transition design guidance will form a valuable tool to inspect, assess and provide guidance for improvement methods and design approaches.

The roll-out of transition specific inspections within the Environment Agency will seek to balance the increased resources required, with the increased confidence this would provide in flood defence performance. A phased roll-out is planned to allow for iterative learning, with the initial focus being on a smaller number of higher risk transitions. Alongside looking to minimise the financial and staff resources for inspection/assessment, these initial phases will explore how transitions with non-flood defence structures can be more readily identified systematically.
Alongside these updates to Environment Agency processes, the learning from the project/pilots about unsuitable designs and maintenance practises are already being fed back into the business, prior to formal release of the design guide.

The reliability analysis tool (hrRELIABLE) for transitions has been incorporated into a web interface (Figure 9) which previously existed to permit Environment Agency staff to generate bespoke fragility curves for nontransition assets

\section{References}

1. Bown, C., Chatterton, J. and Purcell, A. (2014) Asset performance tools - asset inspection guidance. Report - SC110008/R2. Bristol: Environment Agency

2. CIRIA (2013) The International Levee Handbook. C731. London: CIRIA. 
3. Environment Agency (2012) Condition assessment manual. Managing flood risk. Bristol: Environment Agency.

4. Gouldby, B. Sayers, P. Mulet-Marti, J. Hassan, M. and Benwell, D. (2008) A methodology for regional-scale flood risk assessment. Proceedings of the Institution of Civil Engineers, Water Management 161 (3).

5. Hewlett, H., Boorman, L. and Bramley, M. 1987 Design of reinforced grass waterways. CIRIA REPORT 116. London: CIRIA.

6. HR Wallingford (2014) Improved generic fragility curves for use in flood risk analysis. Wallingford: HR Wallingford. Report MCS0941-RT002-R05.

7. ICOLD (2016a) Internal erosion of existing dams, levees and dikes and their foundations. Bulletin 164. Volume 1: Internal erosion processes and engineering assessment. Paris: ICOLD.

8. ICOLD (2016b) Internal erosion of existing dams, levees and dikes and their foundations. Bulletin 164. Volume 2: case histories, investigations, testing, remediation and surveillance.Paris: ICOLD.

9. Morris, M., Benahmed, N., Philippe, P. Royet, P., Tourment, R., van den Ham, G., van Beek, V.. (2012) WP3: Reliability of Urban flood defences - D3.1 Guidance on improved performance of urban flood defences. Report number WP03-01-1211FloodProBE (www.floodprobe.eu).

10. Simm, J., Gouldby, B, Sayers, P., Flikweert, J, Wersching, S and Bramley, B, 2008. Representing fragility of flood and coastal defences: getting into the detail. Proc. Eur. Conf. on Flood Risk Management: Research into Practice (FLOODrisk 2008). London: Taylor \& Francis, 621-631.

11. Simm, J. and Tarrant, O. (2018) Development of fragility curves to describe the performance of UK levee systems. Proceedings ICOLD 26th Congress, Vienna.

12. Simm, J., Flikweert, J-J, Hollingsworth, C. and Tarrant, O. (2017) Ten years of lessons learned from English levee performance during severe flood events. Proc. 85th Annual Meeting of International Commission on Large Dams, Prague.

13. Steendam, G.J., van Hoven, A, van der Meer, J.W., Hoffmans, G. (2014). Wave Overtopping Simulator tests on transitions and obstacles at grass covered slopes of dikes. Proc. ICCE 2014, Seoul, South Korea, ASCE.

14. Tourment, R., Royet, P., Morris, M. (2015) Comprehensive report on Action 3.1.2: Structure transitions. Report number WP03-01-12-10. 1 FloodProBE (www.floodprobe.eu).

15. USACE (2011) Interagency Performance Evaluation Taskforce (IPET): Performance Evaluation of the New Orleans and Southeast Louisiana Hurricane Protection System. Available from https://www.hsdl.org/?abstract\&did=479358.

16. USACE (2020) Conduits, pipes and culverts associated with levees and dams. Engineering Manual 1110-2-2902. Draft version provided by the authors.

17. Van Steeg, P., Labrujere, A., Mom, R. (2015) Transitions structure in grass covered slopes of primary flood defences tested with the wave impact generator. E-Proceedings of the $36^{\text {th }}$ IAHR World Congress, 28 June-3 July, The Hague, The Netherlands.

18. van Bergeijk, V.M. (2018), The effects of transitions on wave overtopping flow and dike cover for flood deference reliability: literature review. CE\&M Research Report 2018R-002/WEM-002. Twente: University of Twente.

19. Verheij, H., Hoffmans, G. and van der Meer, J. (2013) Evaluation and Model Development Grass Erosion Test at the Rhine dike (Release 1). Delft: Deltares.

20. Verheij, H., Hoffmans, G. van der Meer, J. and van Hoven, A. (2015), Evaluation and Model Development Grass Erosion Test at the Rhine dike. (release 4). Delft: Deltares.

21. Vrouwenvelder, A.C.W.M., Steenbergen, H.M.G.M. and Slijkhuis, K.A.H., (2001). Theoretical manual of PC-Ring, Part A: descriptions of failure modes (in Dutch), Nr. 98-CON-R1430, Delft.

22. Whitehead, E. and Nickersons of Rothwell. 1976. A guide to the use of grass in hydraulic engineering practice. CIRIA Technical Note 71 . London: CIRIA. 